\title{
Martensite Transformation Start Temperature During Quench and Austempering in Fe-8Ni-0.2C Alloys
}

\author{
HIROYUKI KAWATA, KUNIO HAYASHI, CHISATO WAKABAYASHI, \\ NAOKI YOSHINAGA, and MANABU TAKAHASHI
}

\begin{abstract}
It is important for the improvement of mechanical properties of quenching and partitioning (QP) steels to control the martensite transformation behavior and the stability of untransformed austenite. In this study, we evaluated the martensite transformation restart temperature $\left(M_{\mathrm{r}}\right)$ via a dilatometer during the reheat austempering pattern. This heat pattern corresponding to the typical heat treatment for $\mathrm{QP}$ steel involves quenching to $T_{\mathrm{Q}}$, a temperature between the martensite transformation start temperature $\left(M_{\mathrm{s}}\right)$ and the finish temperature, and austempering above $M_{\mathrm{s}}$. In Fe-8Ni-0.2C alloy, $M_{\mathrm{r}}$ equals $T_{\mathrm{Q}}$, regardless of the progress of bainite transformation during austempering at $673 \mathrm{~K}\left(400{ }^{\circ} \mathrm{C}\right)$. In Fe-8Ni-1Si-0.2C alloy, $M_{\mathrm{r}}$ decreases parabolically from $T_{\mathrm{Q}}$ with the progress of bainite transformation, and this behavior corresponds to the assumed carbon concentration by bainite transformation. These results indicate that the self-stabilization of the entire untransformed austenite during the first quench from $M_{\mathrm{s}}$ to $T_{\mathrm{Q}}$ was preserved, regardless the bainite transformation. Moreover, the stabilization by the carbon concentration in untransformed austenite was added to this self-stabilization.
\end{abstract}

https://doi.org/10.1007/s11661-021-06167-y

(c) The Minerals, Metals \& Materials Society and ASM International 2021

\section{INTRODUCTION}

HiGH-STRENGTH steel sheets containing multiple structures are widely used in a variety of different applications. To improve these sheets, it is important to understand the transformation behaviors of their constituent structures and control them to produce a desirable microstructure. In particular, in steel in which structures are continuously formed, the interaction between these structures affects their individual transformation behavior. For example, the transformation of ferrite affects the bainite and martensite transformation kinetics ${ }^{[1]}$ concentrating the carbon and manganese contents in austenite, while simultaneously producing an active nucleation site, the ferrite/austenite phase

HIROYUKI KAWATA and CHISATO WAKABAYASHI are with the Steel Research Laboratories, Nippon Steel Corporation, Futtsu 293-8511, Japan. Contact e-mail: kawata.z84.hiroyuki@jp.nipponsteel.com KUNIO HAYASHI is with the Nagoya Works, Nippon Steel Corporation, Tokai, 4768686, Japan. NAOKI YOSHINAGA is with the $\mathrm{R}$ amp;D Laboratories, Nippon Steel Corporation, Futtsu 293-8511, Japan. MANABU TAKAHASHI is with the R\&D Laboratories, Nippon Steel Corporation and also with the Faculty of Engineering Sciences, Kyushu University, Kasuga, 816-8580, Japan.

Manuscript submitted September 30, 2020; accepted December 31, 2020.

Article published online February 19, 2021 boundary. The former depresses while the latter accelerates the bainite and martensite transformations.

Recently, the strength of advanced steels has increased from common high strength steels (e.g., high strength low alloy steels and dual phase steels), resulting in a shift of the main structures from ferrite to hard structures, e.g., martensite and bainite. ${ }^{[2-4]}$ Quenching and partitioning (QP) steel ${ }^{[5]}$ is a typical advanced high-strength steel (AHSS) that can be classified as a 3rd generation AHSS. ${ }^{[2,6]}$ Ideal QP steel contains martensite tempered during partitioning (= austempering) and retained austenite; as such, the only structure in this steel whose transformation behavior would need to be controlled is martensite. ${ }^{[7]}$ However, actual QP steel contains not only tempered martensite and retained austenite but also bainite and fresh martensite. ${ }^{[8-10]}$ In this case, bainite is generated in the austenite + pre-existing martensite structure, and fresh martensite is generated in the austenite + pre-existing martensite + bainite structure. The microstructure ${ }^{[11-13]}$ and properties $^{[13-15]}$ of QP steel depend on the quench temperature and austempering conditions (temperature and time). Therefore, the consideration of the interactions between the transformation behaviors of pre-existing martensite, bainite, and fresh martensite is very important in the optimization of the heat treatment conditions for QP steels. 
To clarify these interactions, it is important to evaluate them with respect to the carbon distribution. Although the carbon distribution depends on the precipitation behavior of ferrous carbide, it is not easy to measure accurately. ${ }^{[16]} \mathrm{A}$ beneficial way for understanding the interaction with/without carbon distribution is to measure it in silicon-free steel. In silicon-free steel, cementite precipitates easily at the partitioning temperature; thus, the carbon in pre-existing martensite and bainite does not transfer to untransformed austenite. For example, in low-alloyed TRIP steel containing silicon, ${ }^{[17-20]}$ the bainite transformation decreases the martensite transformation start temperature $\left(M_{\mathrm{s}}\right)$; however, in silicon-free steel, the effect of bainite transformation on $M_{\mathrm{s}}$ is small. ${ }^{[18]}$ This means that the presence of bainitic ferrite does not affect the fundamentals of martensite transformation. ${ }^{[19]}$ Regarding QP steel, we had already reported the effect of pre-existing martensite on the bainite transformation behavior in silicon-free steels. ${ }^{[21]}$ In addition, Toji et al. ${ }^{[22]}$ compared the bainite transformation behaviors with and without silicon.

In this study, we focused on the martensite transformation start after austempering, which corresponds to the thermal stability of this austenite of residual untransformed austenite. The aim of austempering in the QP process is to decrease the $M_{\mathrm{s}}$ to below room temperature to obtain retained austenite which improve elongation to overcome the limitation for the application of high strength steels owing to their poor formability. ${ }^{[2]}$ There are many studies that focus on the stability of untransformed austenite during the QP process through the carbon enrichment $t^{[5,7,10-12]}$ and morphology ${ }^{[8,23-25]}$ of austenite. However, it is not clear how effective these aspects are. We measured $M_{\mathrm{s}}$ with several heat treatments in $\mathrm{Fe}-\mathrm{Ni}-\mathrm{C}$ with and without silicon alloys and attempted to clarify the effect of the presence of pre-existing martensite and bainite in the QP process.

\section{EXPERIMENTAL PROCEDURES}

Table I shows the chemical compositions of two Fe-Ni-C alloys used in this study. They contain 8 mass pct nickel and 0.20 mass pet carbon. 0Si alloy contains no silicon, whereas $1 \mathrm{Si}$ alloy represents 1 mass pct silicon. Ingots of the alloys melted in vacuum were heated to $1523 \mathrm{~K}\left(1250{ }^{\circ} \mathrm{C}\right)$ and hot-rolled over $1173 \mathrm{~K}$ $\left(900{ }^{\circ} \mathrm{C}\right)$ to make plates with $3 \mathrm{~mm}$ thickness. These plates were ground to remove the decarburized layer around both surfaces and cold-rolled to sheets with 1.0 $\mathrm{mm}$ thickness. These sheets were cut to small specimens with dimensions of $10 \mathrm{~mm} \times 80 \mathrm{~mm}$.

Table I. Chemical Compositions of Alloys Used (Mass Pct)

\begin{tabular}{lccccccc}
\hline Alloy & $\mathrm{C}$ & $\mathrm{Si}$ & $\mathrm{Mn}$ & $\mathrm{Ni}$ & $\mathrm{Al}$ & $\mathrm{N}$ & $\mathrm{Fe}$ \\
\hline OSi & 0.20 & $<0.01$ & $<0.01$ & 7.97 & 0.03 & 0.001 & bal. \\
1Si & 0.20 & 1.00 & $<0.01$ & 8.08 & 0.03 & 0.001 & bal. \\
\hline
\end{tabular}

These specimens were heated via electrical heating and cooled by nitrogen gas with several heat patterns, as shown in Figure 1. We treated specimens with four typical patterns after austenitization at $1373 \mathrm{~K}\left(1100{ }^{\circ} \mathrm{C}\right)$ for 60 second. Figure 1(a) shows a normal quenching (NQ) pattern, in which a specimen was quenched from $1373 \mathrm{~K}\left(1100{ }^{\circ} \mathrm{C}\right)$ to room temperature, $298 \mathrm{~K}\left(25^{\circ} \mathrm{C}\right)$, with a continuous cooling rate of $-30 \mathrm{~K} / \mathrm{s}$. Figure 1(b) shows a two-step quenching (TSQ) pattern, in which a specimen was quenched from $1373 \mathrm{~K}\left(1100{ }^{\circ} \mathrm{C}\right)$ to the quenching temperature $\left(T_{\mathrm{Q}}\right)$. After the first quench to $T_{\mathrm{Q}}$, the specimen was reheated above $M_{\mathrm{s}}$ and quenched to room temperature without any isothermal holding. $T_{\mathrm{Q}}$ resides between $M_{\mathrm{S}}$ and the martensite transformation finish temperature $\left(M_{\mathrm{f}}\right)$, and we maintained it there to make several volume fractions of pre-existing martensite. Figure 1(c) shows a austempering (AT) pattern, in which a specimen was cooled from $1373 \mathrm{~K}$ to $673 \mathrm{~K}$ $\left(1100{ }^{\circ} \mathrm{C}\right.$ to $\left.400{ }^{\circ} \mathrm{C}\right)$ and quenched to room temperature after holding at $673 \mathrm{~K}\left(400{ }^{\circ} \mathrm{C}\right)$, between the bainite transformation start temperature $\left(B_{\mathrm{s}}\right)$ and $M_{\mathrm{s}}$. We controlled the austempering time $\left(t_{\mathrm{AT}}\right)$, which was the holding time at $673 \mathrm{~K}$, to make several volume fractions of bainite. Figure 1(d) shows a reheat austempering (RAT) pattern, in which a specimen was quenched from $1373 \mathrm{~K}\left(1100{ }^{\circ} \mathrm{C}\right)$ to $T_{\mathrm{Q}}$, reheated to $673 \mathrm{~K}\left(400{ }^{\circ} \mathrm{C}\right)$, held at $673 \mathrm{~K}\left(400{ }^{\circ} \mathrm{C}\right)$ for $t_{\mathrm{AT}}$, and quenched to room temperature. This RAT pattern corresponds to a typical $\mathrm{QP}$ process, and the holding at $673 \mathrm{~K}\left(400{ }^{\circ} \mathrm{C}\right)$ corresponds to the partitioning treatment. ${ }^{[7]}$ However, in this study, we refer to this pattern and isothermal holding as RAT and austempering, respectively, because we used a 0Si alloy in which the carbon partitioning from martensite to austenite did not occur.

We evaluated the transformation behavior during heat treatment on a dilatation curve, obtained using a laser displacement meter. Figure 2 shows the schematic of typical dilatation curve after austenitization during the RAT pattern. The dilatation curve starts at " $A$ " in Figure 2. From A to B, the fully austenite structure shrinks linearly. At B, the volume expands owing to the start of the martensite transformation. We stop the first quenching at $T_{\mathrm{Q}}$, and the martensite transformation, which produces pre-existing martensite, occurs from B to $\mathrm{C}$ in Figure 2. The reheating from $T_{\mathrm{Q}}$ to $673 \mathrm{~K}$ (400 $\left.{ }^{\circ} \mathrm{C}\right)$ corresponds to the line $\overline{\mathrm{CD}}$. During austempering at $673 \mathrm{~K}\left(400{ }^{\circ} \mathrm{C}\right)$, the bainite transformation results in a volume expansion from $\mathrm{D}$ to $\mathrm{E}$. Then, the specimen is quenched again from $673 \mathrm{~K}\left(400{ }^{\circ} \mathrm{C}\right)$ to room temperature. From $\mathrm{E}$ to $\mathrm{F}$, the complex structure consisting of untransformed austenite, bainite, and pre-existing martensite, which is tempered at $673 \mathrm{~K}\left(400{ }^{\circ} \mathrm{C}\right)$, shrinks linearly. At $\mathrm{F}$, the volume expands again, as the martensite transformation restarts with decreasing temperature. We refer to the temperature at $\mathrm{F}$ as the martensite transformation restart temperature $\left(M_{\mathrm{r}}\right)$. The volume expansion finishes at $\mathrm{G}$, at temperature $\mathrm{M}_{\mathrm{f}}$, and the line from $\mathrm{G}$ to $\mathrm{H}$ is straight.

The volume fraction of pre-existing martensite $\left(V_{\mathrm{M}}\right)$ is evaluated by the following Eq. [1], in which $X$ and $Z$ are 


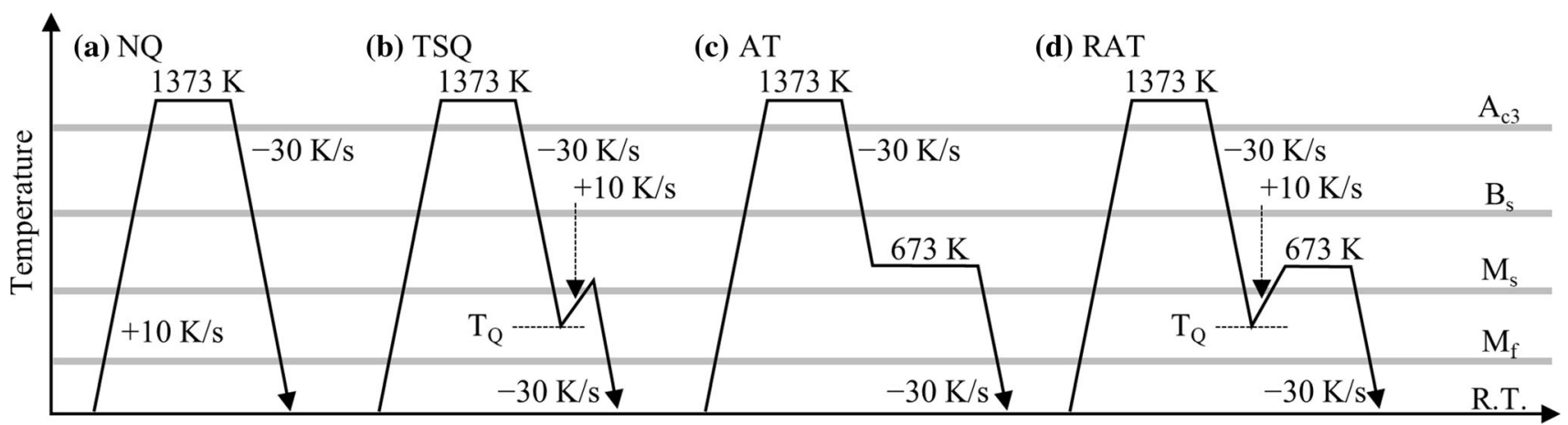

Time

Fig. 1-Schematic of heat treatment patterns in this study. (a) NQ: normal quenching, (b) TSQ: two step quenching, (c) AT: austempering, (d) RAT: reheat austempering, $T_{\mathrm{Q}}$ : quenching temperature.

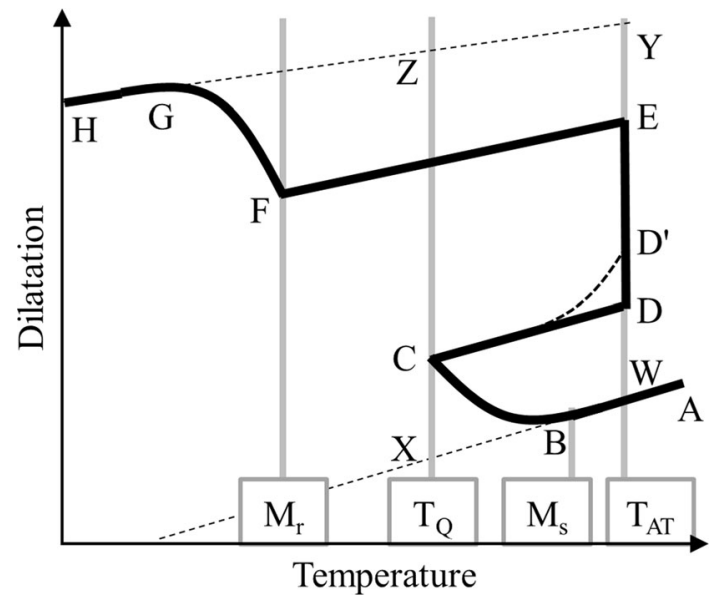

Fig. 2-Schematic dilatation curve during the RAT treatment after austenitization. $T_{\mathrm{AT}}$ : austempering temperature, $673 \mathrm{~K}$ in this study. $T_{\mathrm{Q}}$ : quenching temperature, $M_{\mathrm{r}}$ : martensite transformation restart temperature.

the values at $T_{\mathrm{Q}}$ of the extension of lines $\overline{\mathrm{AB}}$ and $\overline{\mathrm{GH}}$, respectively.

$$
V_{\mathrm{M}}=\overline{\mathrm{CX}} / \overline{\mathrm{ZX}}
$$

The volume fraction of bainite $\left(V_{\mathrm{B}}\right)$ should be evaluated from the length of $\overline{\mathrm{DE}}$. However, in the RAT pattern, the bainite transformation sometimes starts during reheating from $T_{\mathrm{Q}}$ to $673 \mathrm{~K}\left(400{ }^{\circ} \mathrm{C}\right)$, because the bainite transformation was accelerated by the pre-existing martensite. ${ }^{[21]}$ Thus, the dilatation curve is often drawn from $\mathrm{C}$ to $\mathrm{D}^{\prime}$ as the dot curve in Figure 2. For that reason, $V_{\mathrm{B}}$ is evaluated by the following Eq. [2], in which $Y$ is the value at $673 \mathrm{~K}\left(400{ }^{\circ} \mathrm{C}\right)$ of the extension of line $\overline{\mathrm{GH}}$.

$$
V_{\mathrm{B}}=\left(V_{\mathrm{B}}+V_{\mathrm{M}}\right)-V_{\mathrm{M}}=\overline{\mathrm{EW}} / \overline{\mathrm{YW}}-\overline{\mathrm{CX}} / \overline{\mathrm{ZX}}
$$

$M_{\mathrm{r}}$ corresponds to the thermal stability of untransformed austenite after austempering in the RAT process. In QP steel, if $M_{\mathrm{r}}$ is much higher than room temperature, most of the untransformed austenite

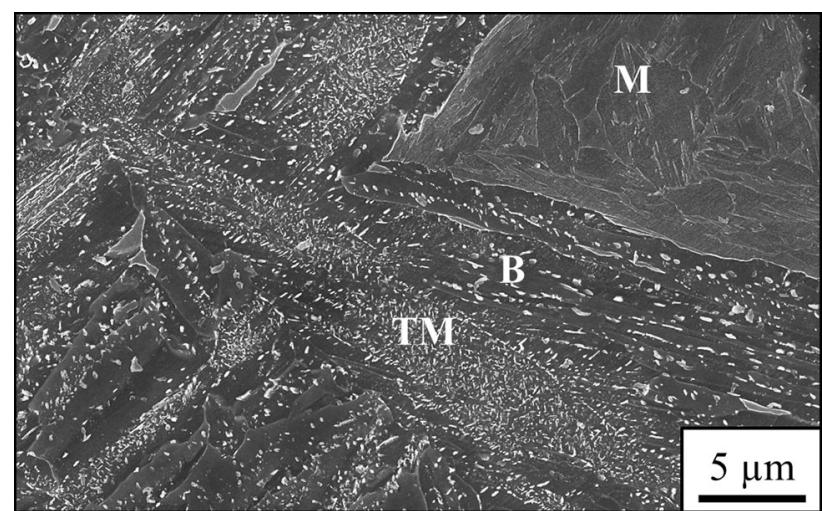

Fig. 3-FE-SEM image of $\mathrm{Fe}-8 \mathrm{Ni}-0.2 \mathrm{C}$ alloy treated with RAT pattern. ${ }^{[26]} \mathrm{M}, \mathrm{B}$, and $\mathrm{TM}$ in the figure correspond to fresh martensite, bainite, and tempered martensite, which is transformed between $M_{\mathrm{S}}$ and $T_{\mathrm{Q}}$ during the first quench. Adapted from ${ }^{[24]}$, with permission.

transforms to fresh martensite, whereas there is still a small amount of retained austenite. We compared $M_{\mathrm{r}}$ in the TSQ and RAT patterns and $M_{\mathrm{S}}$ in the NQ and AT patterns with $V_{\mathrm{M}}$ and $V_{\mathrm{B}}$.

We observed the microstructure etched with nital in the transversal direction at a quarter of the specimen thickness via field-emission scanning electron microscopy (FE-SEM, JEOL-6500F).

\section{RESULTS}

\section{A. Fe-8Ni-0.2C Alloy}

Figure 3 shows an FE-SEM image of the OSi alloy specimen treated with the RAT pattern ${ }^{[26]}$ This specimen was quenched to $T_{\mathrm{Q}}, 570 \mathrm{~K}\left(297^{\circ} \mathrm{C}\right)$, and held at $673 \mathrm{~K}$ $\left(400{ }^{\circ} \mathrm{C}\right.$ ) for $t_{\mathrm{AT}}, 30$ second. Its $V_{\mathrm{M}}$ and $V_{\mathrm{B}}$, which were evaluated from the dilatation curve, were 0.43 and 0.45 , respectively. Thus, its residual volume fraction, 0.12 , corresponds to untransformed austenite just after austempering. In Figure 3, there are three typical structures. ${ }^{[22]}$ The lath-shaped ferrite (black layer) containing large cementite particles (white particles) is bainite ("B" in Figure 3). Ferrite containing many small 
cementite particles is tempered martensite ("TM" in Figure 3), which was pre-existing martensite tempered during austempering. Moreover, the other gray layer ("M" in Figure 3) is fresh martensite (lath martensite without tempering), which was transformed from untransformed austenite during the final quenching from $673 \mathrm{~K}\left(400{ }^{\circ} \mathrm{C}\right)$ to room temperature. Pre-existing martensite was covered by bainite, ${ }^{[21,22]}$ because it accelerates the nucleation of bainitic ferrite. There is much cementite in pre-existing martensite and bainite, which indicates that the carbon distribution to untransformed austenite does not occur.

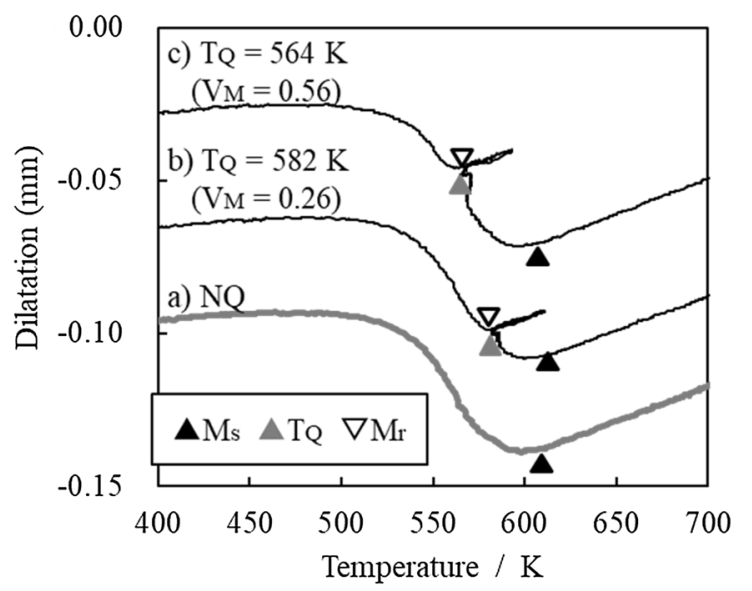

(1)

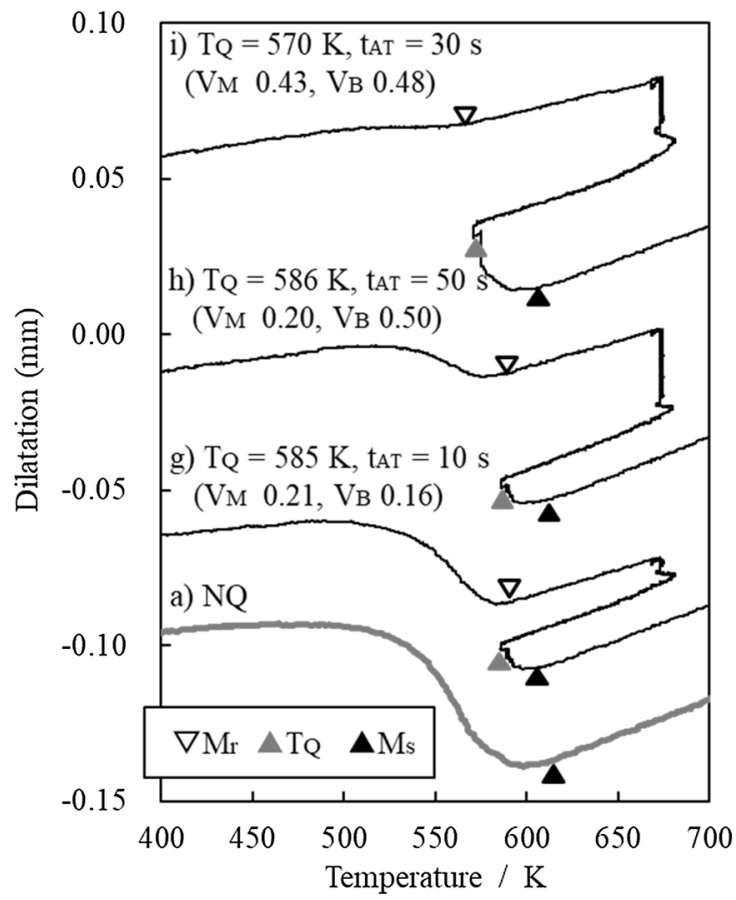

(3)
Figure 4 shows dilatation curves of 0Si specimens with several heat treatments ${ }^{[26]}$ Black, gray, and white triangles correspond to $M_{\mathrm{s}}, T_{\mathrm{Q}}$, and $M_{\mathrm{r}}$, respectively. Figure 4(1) shows the NQ and TSQ curves. $M_{\mathrm{s}}$ and $M_{\mathrm{f}}$ of NQ curve (a) are 606 and $460 \mathrm{~K}\left(333^{\circ} \mathrm{C}\right.$ and $\left.187^{\circ} \mathrm{C}\right)$, respectively. There are two TSQ curves, (b) and (c). Their $T_{\mathrm{Q}}$ are $582 \mathrm{~K}$ and $560 \mathrm{~K}\left(309{ }^{\circ} \mathrm{C}\right.$ and $\left.287{ }^{\circ} \mathrm{C}\right)$; therefore, their $V_{\mathrm{M}}$ are 0.26 and 0.56 , respectively. In these curves, $M_{\mathrm{r}}$ is equal to $T_{\mathrm{Q}}$. Moreover, the martensite transformation behaviors in the TSQ curves are quite similar to that in the NQ curve, except around $T_{\mathrm{Q}}$. This means that the untransformed austenite

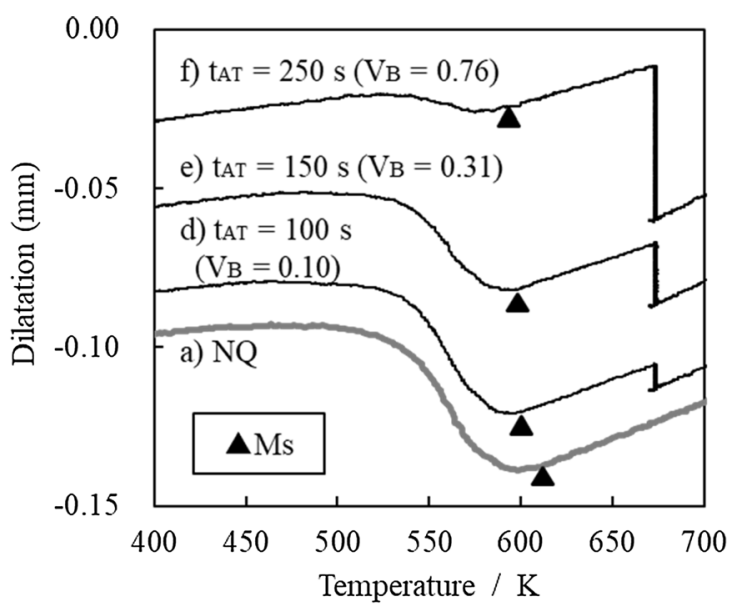

(2)

Fig. 4-Dilatation curves of Fe-8Ni-0.2C alloy during several heat treatments after austenitization. ${ }^{[26]}$ (1) shows the NQ curve, a, and TSQ curves, b and c. (2) shows the AT curves, $\mathrm{d}$, e, and f, with the NQ curve. (3) shows the TSQ curves, g, h, and i, with the NQ curve. $T_{\mathrm{Q}}, t_{\mathrm{AT}}$, $V_{\mathrm{M}}, V_{\mathrm{B}}$, and $M_{\mathrm{r}}$ in the figure correspond to the quenching temperature, austempering time, volume fractions of pre-existing martensite and bainite, and martensite transformation restart temperature, respectively. Adapted from ${ }^{[24]}$, with permission. 
does not become stabilized by partial martensite transformation. ${ }^{[27,28]}$

Figure 4(2) shows the AT curves with the NQ curve. $V_{\mathrm{AT}}$ of AT curves (d), (e), and (f) are 0.10, 0.31, and 0.76 , respectively. $M_{\mathrm{s}}$ in the AT curves is constant, regardless of $V_{\mathrm{B}}$ and $t_{\mathrm{AT}}$, and is almost equal to $M_{\mathrm{S}}$ in the NQ curve. This tendency is in accordance with the findings of the Quidort et al. study regarding silicon-free steel. ${ }^{[18]}$

Figure 4(3) shows the RAT curves with the NQ curve. RAT curves (g), (h), and (i) correspond to the schematic curve shown in Figure 2. RAT specimens (g) and (h) contain almost the same $V_{\mathrm{M}}(0.20$ and 0.21$)$ and different $V_{\mathrm{B}}(0.15$ and 0.50$)$. RAT specimens $(\mathrm{h})$ and (i) contain different $V_{\mathrm{M}}(0.21$ and 0.43$)$ and almost the same $V_{\mathrm{B}}(0.50$ and 0.48$)$. In all RAT curves, $T_{\mathrm{Q}}$ is equal to $M_{\mathrm{r}}$, except for $V_{\mathrm{M}}$ and $V_{\mathrm{B}}$, which depend on $T_{\mathrm{Q}}$ and $t_{\mathrm{AT}}$, respectively. The bainite transformation starts during the reheating from $T_{\mathrm{Q}}$ to $673 \mathrm{~K}\left(400{ }^{\circ} \mathrm{C}\right)$.

Figure 5 shows the effect of bainite transformation on $M_{\mathrm{s}}$ and $M_{\mathrm{r}}$ in several $0 \mathrm{Si}$ specimens ${ }^{[26]}$ The horizontal axis shows the bainite transformation progress parameter $f_{\mathrm{B}}$, which is $V_{\mathrm{B}}$ divided by the volume fraction of austenite at the start of the martensite transformation $\left(=1-V_{\mathrm{M}}\right)$. Open circles and triangles correspond to $M_{\mathrm{S}}$ in the NQ and AT samples, respectively. $M_{\mathrm{s}}$ is $606 \pm 10$ $\mathrm{K}\left(333 \pm 10{ }^{\circ} \mathrm{C}\right)$, the average of $17 \mathrm{NQ}$ samples. $M_{\mathrm{s}}$ in AT samples whose $V_{\mathrm{B}}$ range from 0.03 to 0.76 is stable and does not depend on the progress of the bainite transformation, slightly lower than $606 \mathrm{~K}$ (333 $\left.{ }^{\circ} \mathrm{C}\right)$. Close dots correspond to $M_{\mathrm{r}}$ in the RAT samples, categorized into three groups by their $T_{\mathrm{Q}}$. Their $V_{\mathrm{M}}$ are 0.13 to $0.21,0.33$ to 0.48 , and 0.70 to 0.72 , respectively, from the highest $T_{\mathrm{Q}}$. The three $M_{\mathrm{r}}$ groups stay in each of their $T_{\mathrm{Q}}$ ranges, colored in Figure 5. These tendencies correspond to the dilatation curves of the extracted samples in Figure 4.

Figure 6 shows the relationship between the supercooling during the first quench, $\Delta\left(=M_{\mathrm{s}}-T_{\mathrm{Q}}\right)$, and the change in the thermal stability of untransformed austenite, $\theta$ ( $\left.=M_{\mathrm{s}}-M_{\mathrm{r}}\right)$. Open and closed dots correspond to the TSQ and RAT samples, respectively. ${ }^{[26]}$

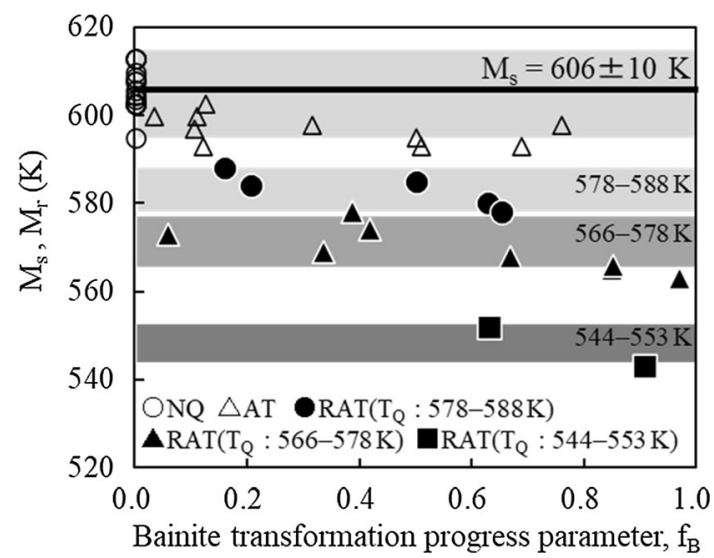

Fig. 5-Effect of bainite transformation on the martensite transformation start temperature $\left(M_{\mathrm{s}}\right)$ and restart temperature $\left(M_{\mathrm{r}}\right)$ in $\mathrm{Fe}-8 \mathrm{Ni}-0.2 \mathrm{C}$ alloy. ${ }^{[26]}$ Adapted from ${ }^{[24]}$, with permission
Furthermore, the RAT samples are categorized into four groups by $f_{\mathrm{B}}$. As depicted in the dilatation curves shown in Figure 4, $M_{\mathrm{r}}$ in the TSQ samples is equal to $T_{\mathrm{Q}}$; therefore, in Figure 6, open dots exist on the gray line. This phenomenon indicates that the first quench expended the unstable part of the austenite; thus, the residual untransformed austenite is more stable than the prior austenite through the supercooling, $\Delta$. This process is referred to as the self-stabilization of austenite. ${ }^{[29]}$

Similarly, the dots of the RAT samples reside near the gray line, regardless of $f_{\mathrm{B}}$ and $\Delta$. This tendency is shown in Figures 4 and 5, indicating that the bainite transformation in the $0 \mathrm{Si}$ alloy does not affect the austenite stability for martensite transformation in the RAT pattern as much as that in the AT pattern. From Figure 3, pre-existing martensite was covered by bainite in the RAT sample, particularly the sample containing a small amount of $V_{\mathrm{M}}$ with large $f_{\mathrm{B}}$. However, the residual untransformed austenite, which was separated from pre-existing martensite by bainite, completely memorized the supercooling during the first quench. We call the supercooling memory effect for this phenomenon; namely, the self-stabilization of the residual untransformed austenite is preserved, regardless the bainite transformation.

\section{B. $\mathrm{Fe}-8 \mathrm{Ni}-1 \mathrm{Si}-0.2 \mathrm{C}$ Alloy}

Figure 7 shows an FE-SEM image of the 1Si alloy specimen treated with the RAT pattern. This specimen was quenched to $T_{\mathrm{Q}}, 574 \mathrm{~K}\left(301{ }^{\circ} \mathrm{C}\right)$, and held at $673 \mathrm{~K}$ $\left(400{ }^{\circ} \mathrm{C}\right.$ ) for $t_{\mathrm{AT}}, 100$ second. Its $V_{\mathrm{M}}$ and $V_{\mathrm{B}}$, evaluated from the dilatation curve, were 0.23 and 0.34 , respectively. There are three typical structures, bainite, pre-existing martensite, and fresh martensite. These constituents are similar to those in the 0Si RAT sample shown in Figure 3. Bainite in the 1Si alloy, "B" in Figure 7 , consists of lath-shaped bainitic ferrite with carbide particles, whose density is lower than that in the

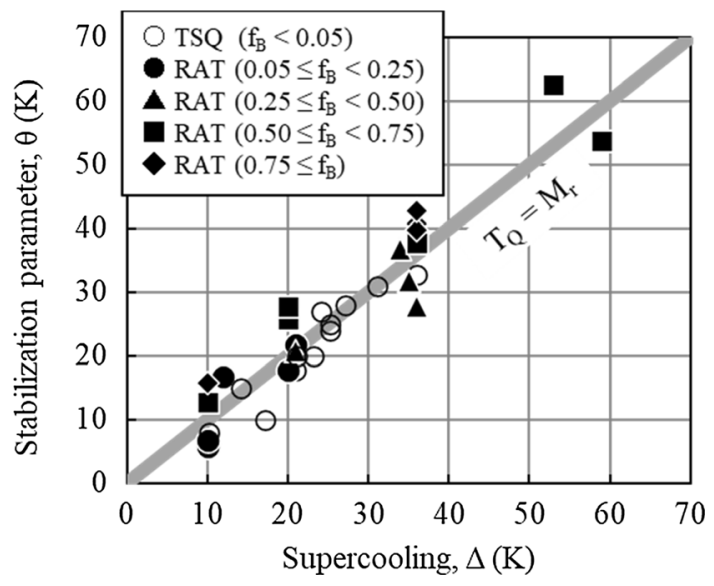

Fig. 6-Relationship between the supercooling during the first quench in the TSQ and RAT patterns and the stabilization parameter, which is the difference between $M_{\mathrm{s}}$ and $M_{\mathrm{r}}$, in $\mathrm{Fe}-8 \mathrm{Ni}-0.2 \mathrm{C}$ alloy ${ }^{[26]}$ The black dots corresponding to RAT data were categorized into four groups by the bainite transformation progress parameter, $f_{\mathrm{B}}$. Adapted from ${ }^{[2]}$, with permission. 


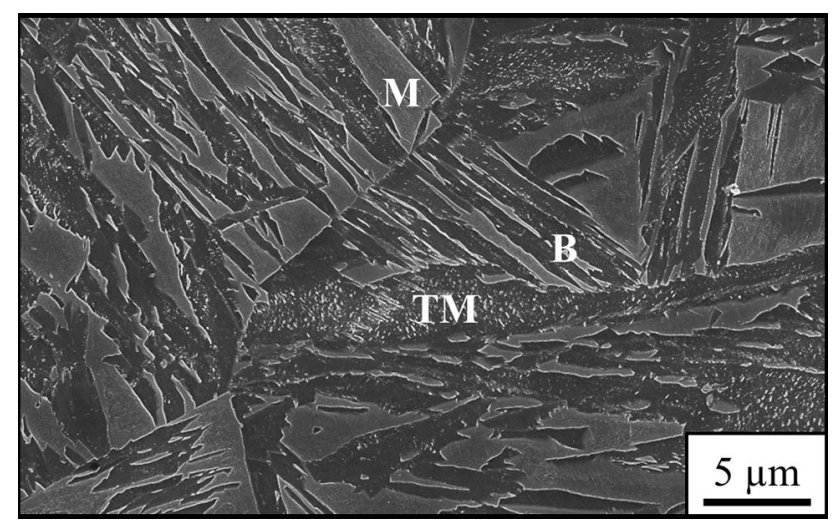

Fig. 7-FE-SEM image of $\mathrm{Fe}-8 \mathrm{Ni}-1 \mathrm{Si}-0.2 \mathrm{C}$ alloy treated with RAT pattern. M, B, and TM in the figure correspond to fresh martensite, bainite, and tempered martensite, which is transformed between $M_{\mathrm{s}}$ and $T_{\mathrm{Q}}$ during the first quench.

0Si alloy. Pre-existing martensite, which was tempered during austempering, contains many small carbide particles as the "TM" layer in Figure 7; thus, it is distinguishable from bainite and fresh martensite. It is difficult to determine the difference in carbide in the pre-existing martensite between the $0 \mathrm{Si}$ alloy and the $1 \mathrm{Si}$ alloy via FE-SEM. Although bainite and tempered martensite are adjacent, bainite does not surround the tempered martensite, which is covered by bainite in the 0Si alloy, as shown in Figure 3. Bainite in the 1Si alloy grows toward the interior of the untransformed austenite, as Toji et al. reported. ${ }^{[22]}$ Therefore, most fresh martensite islands (gray layer in Figure 7), are divided by bainitic ferrite, with their shape and size appearing elongated and small.

Figure 8 shows the dilatation curves of the $1 \mathrm{Si}$ specimens with the several heat treatments (Figure 1). In Figure 8(1), the NQ curve and TSQ curves are similar to those for the $0 \mathrm{Si}$ alloy. $M_{\mathrm{s}}$ is $600 \mathrm{~K}\left(327^{\circ} \mathrm{C}\right)$, and $M_{\mathrm{r}}$ is equal to $T_{\mathrm{Q}}$. Figure $8(2)$ shows the $\mathrm{AT}$ curves, in which $V_{\mathrm{B}}$ ranges from 0.19 to 0.72 . With the progress of bainite transformation, $M_{\mathrm{s}}$ decreases from $600 \mathrm{~K}$ to 553 $\mathrm{K}\left(327{ }^{\circ} \mathrm{C}\right.$ to $\left.280{ }^{\circ} \mathrm{C}\right)$. This stabilization of untransformed austenite depends on the carbon enrichment in austenite. ${ }^{[18-20]}$ In the $1 \mathrm{Si}$ alloy, the solute carbon is distributed from bainite to untransformed austenite owing to the depression of the cementite precipitation, as shown in Figure 7.

Figure 8(3) shows the RAT curves, where the (g), (h), and (i) curves are the results for the same $T_{\mathrm{Q}}$ specimens. They were quenched to $561 \mathrm{~K}\left(288^{\circ} \mathrm{C}\right)$, and the curves approached the level of the pre-existing martensite. The $t_{\mathrm{AT}}$ times were long, equal to 2,40 , and 200 seconds, and $V_{\mathrm{B}}$ increased to $0.06,0.23,0.39$, respectively. Although $M_{\mathrm{r}}$ on $(\mathrm{g})$ is equal to $T_{\mathrm{Q}}$, in the RAT samples, it decreases from $T_{\mathrm{Q}}$ to $496 \mathrm{~K}\left(223{ }^{\circ} \mathrm{C}\right)$ with the progress of bainite transformation, just as in the AT curves. The curves representing the specimens of (i) and (j) exhibit similar $V_{\mathrm{B}}, 0.39$ and 0.34 , and significantly different $V_{\mathrm{M}}$,
0.46 and 0.23 . The differences for $T_{\mathrm{Q}}$ and $M_{\mathrm{r}}$ are $65 \mathrm{~K}$ and $18 \mathrm{~K}$, respectively, which indicates that $M_{\mathrm{r}}$ in $1 \mathrm{Si}$ alloy decreases with the progress of bainite transformation, and this effect depends on $V_{\mathrm{M}}$.

Figure 9 shows $M_{\mathrm{S}}$ of the NQ and AT samples and $M_{\mathrm{r}}$ of the RAT samples in the $1 \mathrm{Si}$ alloy. The horizontal axis in Figure 9 is $V_{\mathrm{M}}+V_{\mathrm{B}} . M_{\mathrm{s}}$ and $M_{\mathrm{r}}$ seems to decrease similarly with $V_{\mathrm{M}}+V_{\mathrm{B}}$, independent of the breakdown between $V_{\mathrm{M}}$ and $V_{\mathrm{B}}$. From this result, we can assume that carbon partitioning occurred from the pre-existing martensite to untransformed austenite, and pre-existing martensite stabilized the untransformed austenite as much as the bainite, indicating the QP process. ${ }^{[5,7]}$ However, $M_{\mathrm{r}}$ reflects the supercooling during the first quench, which was memorized by the untransformed austenite in the 0Si and the 1Si alloys. This effect does not depend on the carbon partitioning behavior; hence, we have to understand the $M_{\mathrm{r}}$ behavior, considering the carbon partitioning and this supercooling memory effect separately.

The carbon content in untransformed austenite during the RAT pattern at the austempering finish, $C_{\gamma}{ }^{\prime}$ (mass pct), corresponds to the following Eq. [3]. $C_{\gamma}$ is the initial carbon content of the prior austenite, and $X$ and $Y$ are the carbon partitioning coefficients to untransformed austenite from pre-existing martensite and bainite, respectively.

$$
C_{\gamma}^{\prime}=C_{\gamma} \cdot\left(1+\frac{X \cdot V_{\mathrm{M}}+Y \cdot V_{\mathrm{B}}}{1-V_{\mathrm{M}}-V_{\mathrm{B}}}\right)
$$

$V_{\mathrm{B}}$ in the Eq. [3] is replaced by $f_{\mathrm{B}}$ and $V_{\mathrm{M}}$ as the following Eq. [4].

$$
\begin{aligned}
C_{\gamma}^{\prime} & =C_{\gamma} \cdot\left\{1+\frac{X \cdot V_{\mathrm{M}}+Y \cdot f_{\mathrm{B}} \cdot\left(1-V_{\mathrm{M}}\right)}{1-V_{\mathrm{M}}-f_{\mathrm{B}} \cdot\left(1-V_{\mathrm{M}}\right)}\right\} \\
& =C_{\gamma} \cdot\left\{1+\frac{X-\left(X-Y \cdot f_{\mathrm{B}}\right) \cdot\left(1-V_{\mathrm{M}}\right)}{\left(1-f_{\mathrm{B}}\right) \cdot\left(1-V_{\mathrm{M}}\right)}\right\}
\end{aligned}
$$

Then, with the assumption that the partitioning from pre-existing martensite is negligibly small, $X \fallingdotseq 0$ or $V_{\mathrm{M}}$ $\fallingdotseq 0$, this equation become a simple equation that depends on $f_{\mathrm{B}}$.

$$
C_{\gamma}^{\prime}=C_{\gamma} \cdot\left(1+\frac{Y \cdot f_{\mathrm{B}}}{1-f_{\mathrm{B}}}\right)
$$

Figure 10 shows $M_{\mathrm{s}}$ and $M_{\mathrm{r}}$ plotted in Figure 9. The horizontal axis is $f_{\mathrm{B}}$. Open triangles correspond to $M_{\mathrm{S}}$ in the AT samples, in which $f_{\mathrm{B}}$ equals $V_{\mathrm{B}}$. Although these $M_{\mathrm{S}}$ with small $f_{\mathrm{B}}$ stay just below $M_{\mathrm{S}}$ in the NQ samples, the average of the $19 \mathrm{NQ}$ samples is $600 \pm 9 \mathrm{~K}(327 \pm 9$ ${ }^{\circ} \mathrm{C}$ ), and $M_{\mathrm{S}}$ decreases parabolically with an increase in $f_{\mathrm{B}}$.

Closed dots indicate $M_{\mathrm{r}}$ in the RAT samples, and they are categorized into three groups by $T_{\mathrm{Q}}$ (Figure 5). Closed triangles, in which $T_{\mathrm{Q}}$ and $V_{\mathrm{M}}$ are $559 \mathrm{~K}$ to 562 $\mathrm{K}\left(286{ }^{\circ} \mathrm{C}\right.$ to $\left.289{ }^{\circ} \mathrm{C}\right)$ and 0.26 to 0.60 , respectively, 


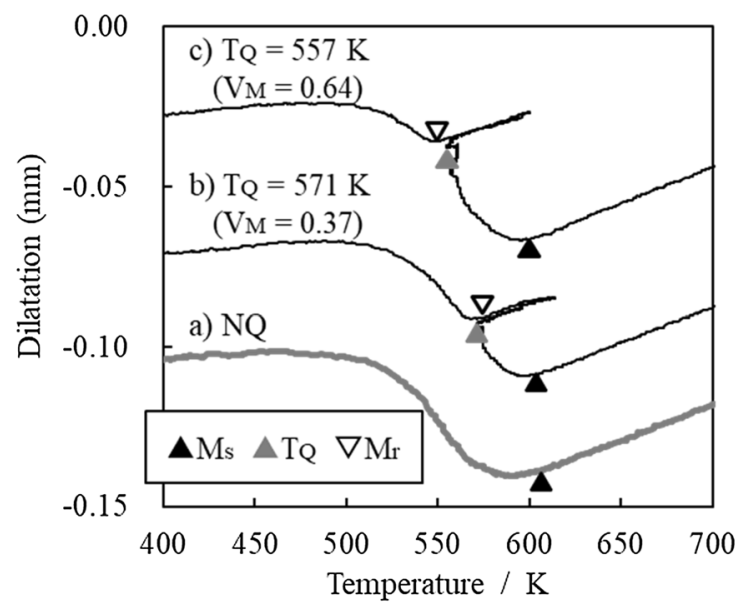

(1)

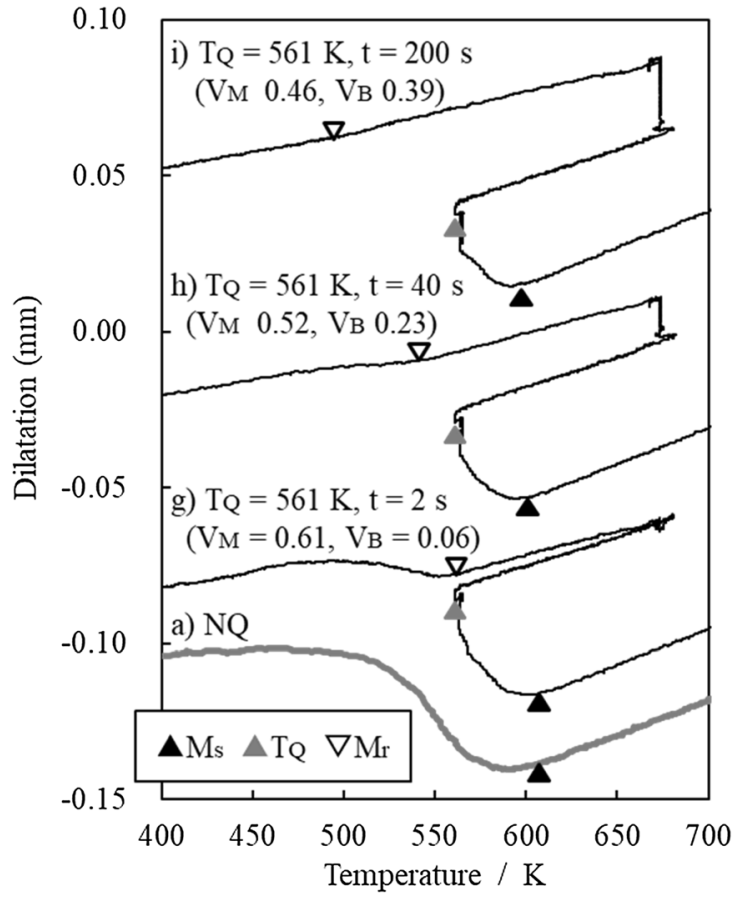

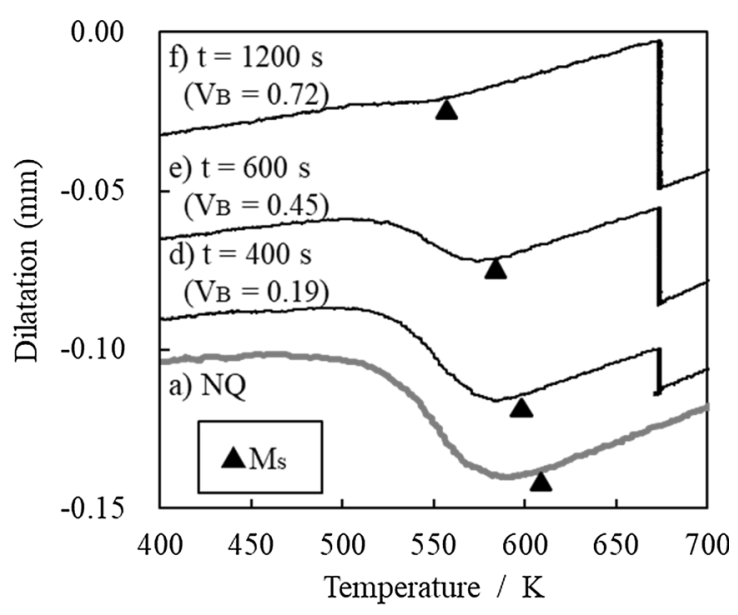

(2)

(3)

Fig. 8-Dilatation curves of $\mathrm{Fe}-8 \mathrm{Ni}-1 \mathrm{Si}-0.2 \mathrm{C}$ alloy during several heat treatments after austenitization. (1) shows the NQ curve, a, and TSQ curves, $b$ and c. (2) shows the AT curves, d, e, and f, with the NQ curve. (3) shows the TSQ curves, $g$, h, and $\mathrm{i}$, with the NQ curve. $T_{\mathrm{Q}}$, $\mathrm{t}_{\mathrm{AT}}$, $V_{\mathrm{M}}, V_{\mathrm{B}}$, and $M_{\mathrm{r}}$ in the figure correspond to the quenching temperature, austempering time, volume fraction of pre-existing martensite, that of bainite, and martensite transformation restart temperature, respectively.

contain the data of the dilation curves $(\mathrm{g}),(\mathrm{h})$, and (i) in Figure 8 , and $f_{\mathrm{B}}$ of these curves is $0.15,0.48$, and 0.73 , respectively. $M_{\mathrm{r}}$ has a value near $T_{\mathrm{Q}}$ for a small amount of $f_{\mathrm{B}}$ and decreases parabolically with increasing $\mathrm{f}_{\mathrm{B}}$. The curve of $M_{\mathrm{r}}$ in Figure 10 is similar to that of $M_{\mathrm{s}}$. The curve $(j)$ in Figure 8 belongs to the closed circles in Figure 10. This group, in which $V_{\mathrm{M}}$ is 0.18 to 0.25 , shows similar behavior as the $T_{\mathrm{Q}} 559 \mathrm{~K}$ to $562 \mathrm{~K}$ (286 ${ }^{\circ} \mathrm{C}$ to $289{ }^{\circ} \mathrm{C}$ ) samples, and $f_{\mathrm{B}}$ is 0.48 . Thus, $M_{\mathrm{r}}$ decreases from $T_{\mathrm{Q}}$ slightly as much as curve $(h)$ with a similar $f_{\mathrm{B}}$. This result suggests that $M_{\mathrm{r}}$ mainly depends on the supercooling during the first quench and the carbon partitioning from bainite to untransformed austenite.

\section{DISCUSSION}

\section{A. Austenite Stabilization with Bainite Transformation}

In the $0 \mathrm{Si}$ alloy, the untransformed austenite at the austempering finish is stabilized for the martensite transformation as much as the supercooling during the first quench, $\Delta$, in the TSQ and RAT heat treatments. Furthermore, bainite transformation does not affect $M_{\mathrm{s}}$ and $M_{\mathrm{r}}$ in the AT and RAT heat treatments.

In the $1 \mathrm{Si}$ alloy, the untransformed austenite after the first quench during the TSQ treatment is stabilized as much as $\Delta$. The untransformed austenite treated with the RAT pattern in the 1Si alloy is expected to memorize $\Delta$ after the bainite transformation during austempering. 


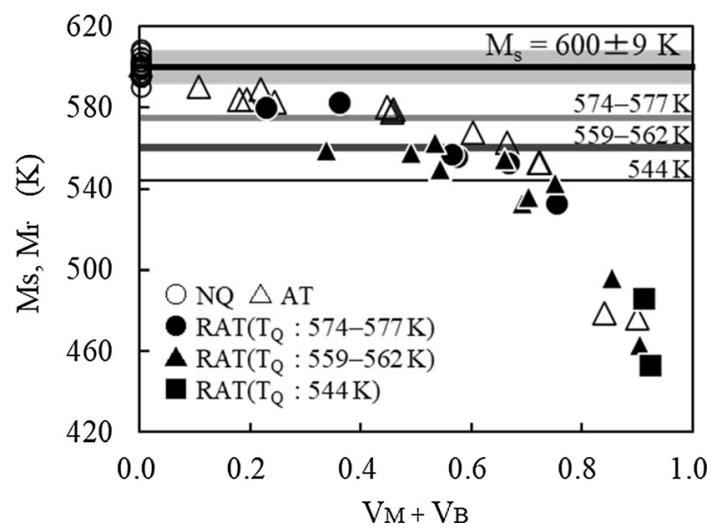

Fig. 9-Relationship between the pre-existing microstructure and martensite transformation start temperature $\left(M_{\mathrm{s}}\right)$ or restart temperature $\left(M_{\mathrm{r}}\right)$ in $\mathrm{Fe}-8 \mathrm{Ni}-1 \mathrm{Si}-0.2 \mathrm{C}$ alloy. $V_{\mathrm{M}}$ and $V_{\mathrm{B}}$ are the volume fractions of pre-existing martensite and bainite, respectively.

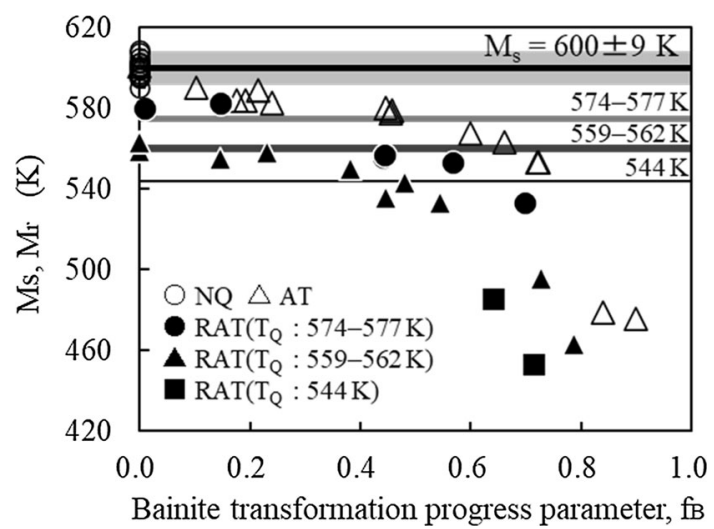

Fig. 10-Effect of bainite transformation on the martensite transformation start temperature $\left(M_{\mathrm{s}}\right)$ and restart temperature $\left(M_{\mathrm{r}}\right)$ in $\mathrm{Fe}-8 \mathrm{Ni}-1 \mathrm{Si}-0.2 \mathrm{C}$ alloy.

This tendency seems to disappear in the RAT samples with small $f_{\mathrm{B}}$, as shown in Figure 10. In addition, the bainite transformation depresses the martensite transformation through the carbon distribution from bainite to untransformed austenite, because $\mathrm{Si}$ delays the precipitation of cementite. Therefore, $M_{\mathrm{r}}$ with large $f_{\mathrm{B}}$ in the $1 \mathrm{Si}$ alloy drops further from $T_{\mathrm{Q}}$.

Figure 11 compares the austenite stabilization by austempering during the AT and RAT patterns. The horizontal axis is the bainite transformation progress parameter, $f_{\mathrm{B}}$, and the vertical axis is $\theta-\Delta$, which corresponds to the decrease in the martensite transformation start temperature during austempering. Figures 11(1) and (2) show the results in the 0Si and the $1 \mathrm{Si}$ alloys, respectively. Open triangles denote the effect of bainite transformation on the AT samples, which contain no pre-existing martensite. In the $0 \mathrm{Si}$ alloy, shown in Figure 11(1), there is no effect or a slightly decreasing effect on $M_{\mathrm{s}}$. Meanwhile, for the RAT samples, represented by closed dots, $M_{\mathrm{r}}$ does not change with austempering.

However, in the $1 \mathrm{Si}$ alloy, $M_{\mathrm{S}}$ of the AT samples decreases parabolically with the progress of bainite transformation. The gray lines in Figure 11(2) correspond to the calculated $M_{\mathrm{s}}$ decreasing by bainite transformation with several carbon partitioning coefficients, $Y$. The effect of carbon concentration on $M_{\mathrm{s}}$, $f(C)$, is evaluated via the following Eq. [6], ${ }^{[30]}$ which is suitable for $M_{\mathrm{s}}$ for a wide range of carbon content, ${ }^{[31]}$ with the estimation of the strain-induced martensite transformation behavior in TRIP steel. ${ }^{[32]}$

$$
\begin{aligned}
f(C)= & 546 \cdot\left\{\exp \left(-1.362 \cdot C_{\gamma}\right)-\exp \left(-1.362 \cdot C_{\gamma}^{\prime}\right)\right\} \\
= & 546 \cdot \exp \left(-1.362 \cdot C_{\gamma}\right) \\
& \cdot\left\{1-\exp \left(-1.362 \cdot C_{\gamma} \cdot \frac{Y \cdot f_{\mathrm{B}}}{1-f_{\mathrm{B}}}\right)\right\}
\end{aligned}
$$

$M_{\mathrm{s}}$ behavior of AT samples in 1Si alloy is similar to the calculation result with $Y=0.2$. This indicates that the effect of austempering on $M_{\mathrm{s}}$ in the AT samples depends on the carbon enrichment of untransformed austenite with bainite transformation.

The results of the RAT samples reside near the parabolic curve drawn with the AT samples. As mentioned above, $f_{\mathrm{B}}$ dominates the carbon concentration behavior of untransformed austenite when the carbon partitioning from pre-existing martensite is small, which suggests that the $M_{\mathrm{r}}$ behavior in the $1 \mathrm{Si}$ alloy mainly depends on the carbon concentration with bainite transformation and the supercooling memory effect, as shown in Figure 6.

In Figure 10(2), closed squares correspond to RAT samples quenched at $544 \mathrm{~K}\left(271{ }^{\circ} \mathrm{C}\right)$ during the first quench, and pre-existing martensite occupied three quarters of their microstructure. Their $t_{\mathrm{AT}}$ and $V_{\mathrm{B}}$ are 20 to 100 second and 0.16 to 0.20 , respectively. Though the change in $V_{\mathrm{B}}$ is only 0.04 , the change in the stabilization from $T_{\mathrm{Q}}$ is $33 \mathrm{~K}$, which corresponds to a carbon concentration of 0.08 mass pct. In this case, $M_{\mathrm{r}}$ in the RAT sample is sometimes moved with slight progress of the bainite transformation, especially with large amount of pre-existing martensite. Furthermore, these closed squares seem to become slightly more stabilized than represented in other RAT samples. This tendency might be due to the carbon partitioning from pre-existing martensite ${ }^{[5,7,10-12]}$ and/or the morphology ${ }^{[8,23-25]}$ of austenite.

\section{B. Model for $M_{r}$ Behavior}

The martensite transformation from the fully austenite structure during the quench progresses gradually with decreasing temperature from $M_{\mathrm{s}}{ }^{[33,34]}$ Figure 12 shows the martensite transformation behavior in the $0 \mathrm{Si}$ alloy during the NQ treatment. The black line represents $V_{\mathrm{M}}$, which increases with decreasing temperature, evaluated from the dilatation curve, Figure 4(a). $V_{M}$ at temperature $T$ can be typically described by the KoistinenMarburger (KM) equation ${ }^{[33]}$ as follows.

$$
V_{\mathrm{M}}=1-\exp \left\{-\alpha \cdot\left(T_{\mathrm{KM}}-T\right)\right\}
$$




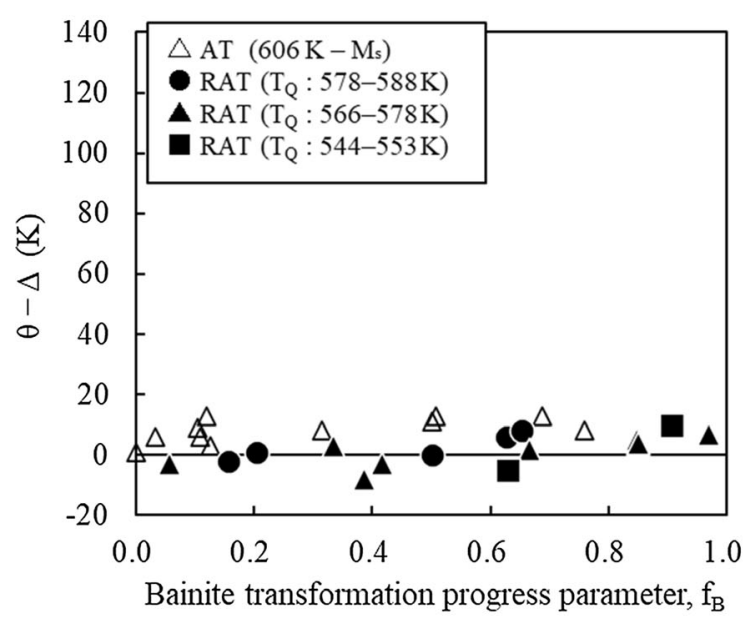

(1)

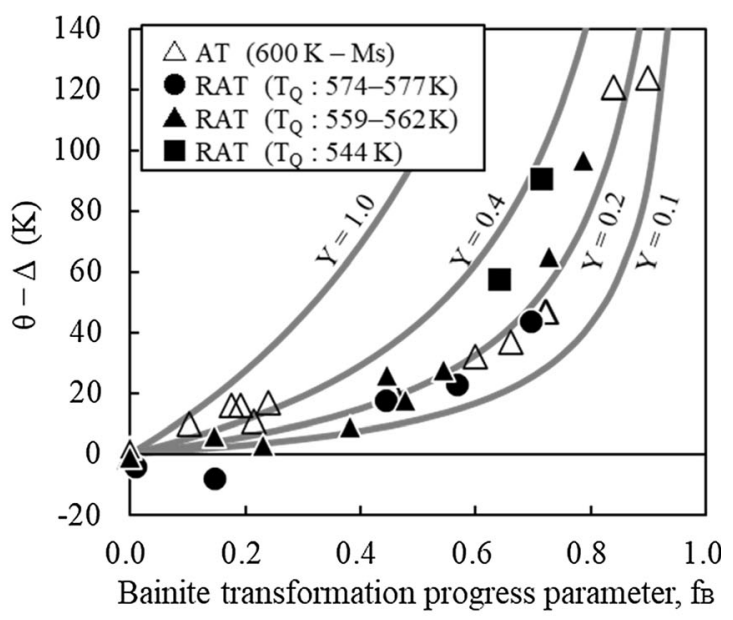

(2)

Fig. 11-Austenite stabilization with the progress of bainite transformation during the AT and RAT treatments on (1) the 0Si alloy and (2) the $1 \mathrm{Si}$ alloy, respectively. $\theta$ is the total stabilization from prior austenite, the difference in $M_{\mathrm{s}}$ in AT samples or $M_{\mathrm{r}}$ in the RAT samples from $M_{\mathrm{s}}$ in NQ samples. $\Delta$ is the supercooling during the first quench in RAT pattern, the difference in $T_{\mathrm{Q}}$, the quenching temperature, from $M_{\mathrm{s}}$ in NQ sample. $\Delta$ in the AT sample is zero.

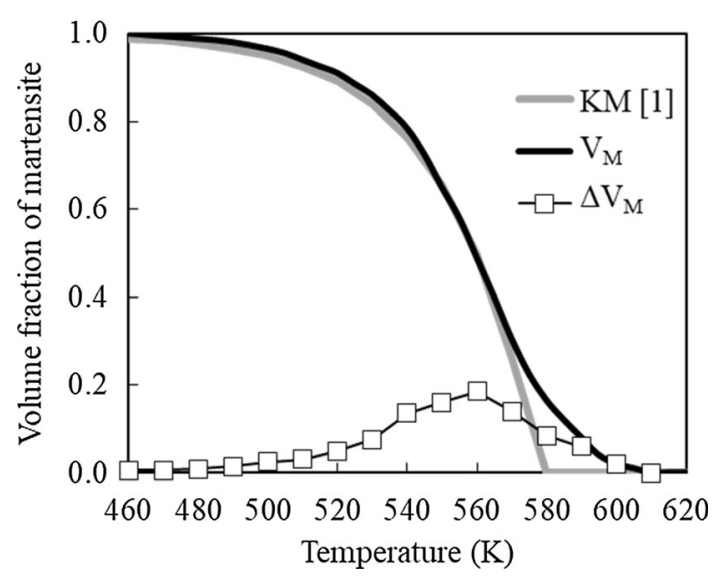

Fig. 12-Martensite transformation behavior in the 0Si alloy during NQ treatment. The black line is measured data by dilatometer. The gray line is calculated results of KM equation ${ }^{[33]}$ with $T_{\mathrm{KM}}=578 \mathrm{~K}$ and $\alpha=0.038 \mathrm{~K}^{-1}$. The square dots correspond to the $V_{\mathrm{M}}$ increment measured every $10 \mathrm{deg}$.

$\mathrm{T}_{\mathrm{KM}}$ in the original equation ${ }^{[33]}$ is $M_{\mathrm{S}}$ and is called the theoretical martensite transformation start temperature; in many cases, ${ }^{[1,12,34,35]}$ this temperature is lower than the measured $M_{\mathrm{s}}$. The gray line in Figure 12 is the calculation result of the $\mathrm{KM}$ equation with $T_{\mathrm{KM}}=578$ $\mathrm{K}\left(305^{\circ} \mathrm{C}\right)$ and $\alpha=0.038 \mathrm{~K}^{-1}$. These results are similar to those of the Zhu et al. study. ${ }^{[1]}$ They evaluated that $\alpha$ varies from 0.031 to $0.039 \mathrm{~K}^{-1}$, and $T_{\mathrm{KM}}$ is always lower than $M_{\mathrm{s}}$ in 0.155 and 0.319 mass pet carbon low-alloyed steels via the dilatometry study.

In steel, when the quench stops at $T_{\mathrm{Q}}$ between $M_{\mathrm{s}}$ and $M_{\mathrm{f}}$, the martensite transformation stops with the volume fraction of martensite equivalent to that of the supercooling from $M_{\mathrm{s}}$. Then, it restarts at $T_{\mathrm{Q}}$ without austempering, just as the TSQ specimens shown in this study and in previous studies. ${ }^{[36,37]}$ This behavior is expected considering the distribution of austenite stability for the martensite transformation. The square dots in Figure 12 shows the increase in $V_{\mathrm{M}}$ every $10 \mathrm{~K}$, corresponding to the observed transformation behavior. Just below $M_{\mathrm{s}}$, the portion transformed to martensite is small, representing a relatively unstable region of prior austenite. The increment increases with decreasing temperature and has a peak at $560 \mathrm{~K}\left(287^{\circ} \mathrm{C}\right)$. Below the peak, it decreases, and the portion around $M_{\mathrm{f}}$ is small, representing a relatively stable region of prior austenite. This change in $V_{\mathrm{M}}$ increment reflects the distribution of the thermal stability of austenite to martensite transformation.

Figure 13 shows the schematics to explain the $M_{\mathrm{s}}$ behaviors during the NQ and AT treatments in this study. There is no pre-existing martensite. Figures 13(1), (3), and (5) show the transformation behavior, and (2), (4), and (6) represent the distributions of the austenite stability at $M_{\mathrm{s}}$. In the NQ treatment, (1) and (2), these schematics correspond to the black line and the square dots in Figure 12. The martensite transformation proceeds according to the distribution with decreasing temperature. $M_{\mathrm{s}}$ is determined by the most unstable region in the distribution.

Figures 13(3) and (4) describe the case of the AT sample without silicon. Before the martensite transformation, the bainite transformation proceeds above $M_{\mathrm{s}}$ in the NQ sample. However, $M_{\mathrm{s}}$ does not change from $M_{\mathrm{s}}$ in the NQ sample (Figure 4(2)). This result suggests that the bainite transformation at $673 \mathrm{~K}\left(400{ }^{\circ} \mathrm{C}\right)$ does not change the shape of the distribution but rather the height of the peak, which means the volume fraction.

Silicon in steel depresses the carbide precipitation in bainite; thus, the carbon concentration of untransformed austenite behaves as in the bainite transformation. Although the bainite transformation does not affect the fundamentals of martensite transformation ${ }^{[19]}$ (Figure 13(4)), the stability of austenite shifts to stable side according to the enrichment of the carbon 


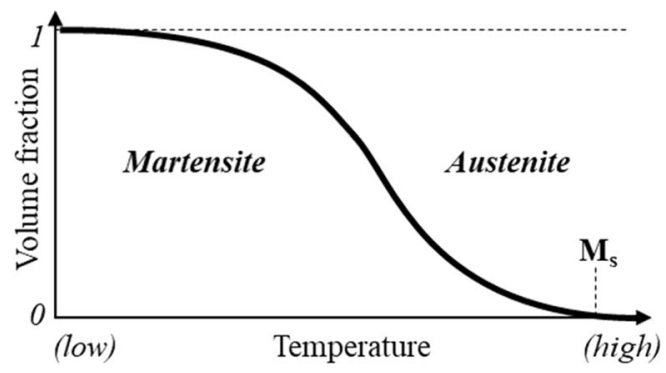

(1)

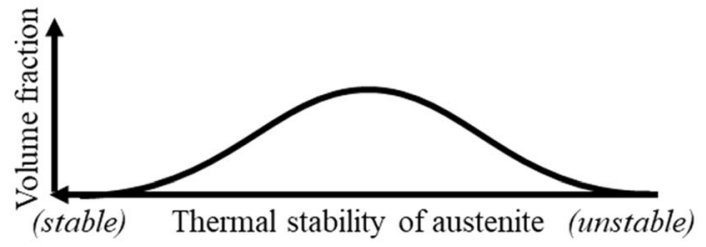

(2)

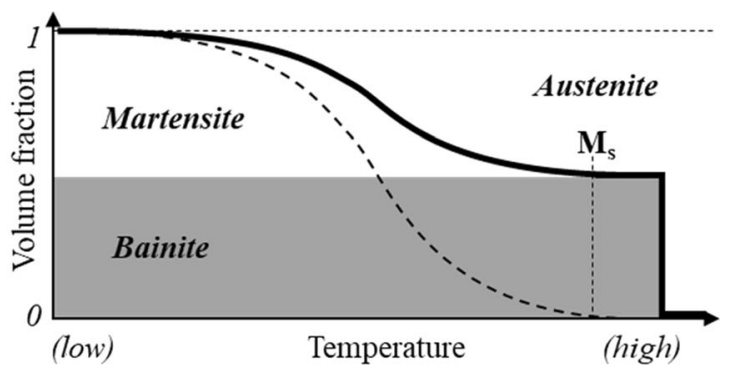

(3)

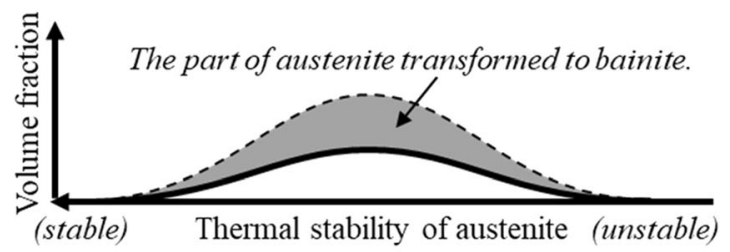

(4)

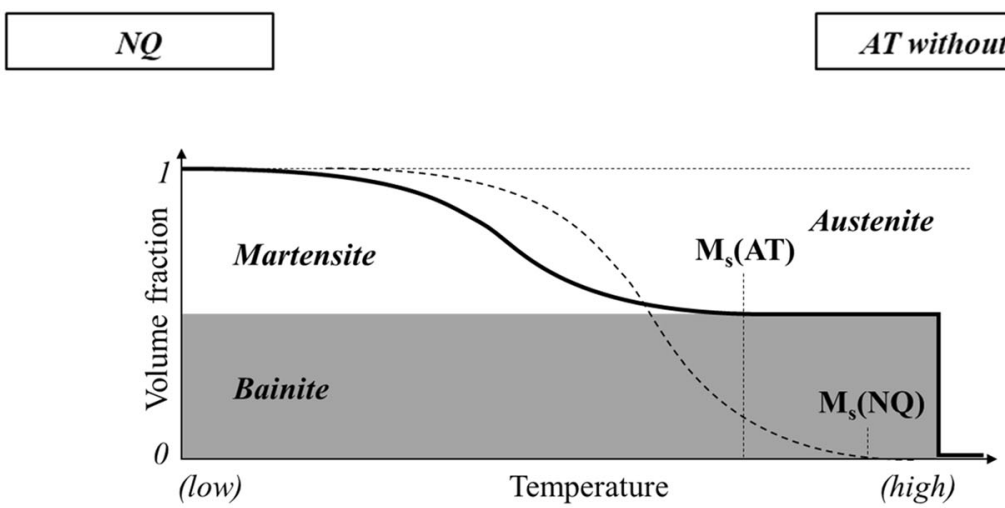

(5)

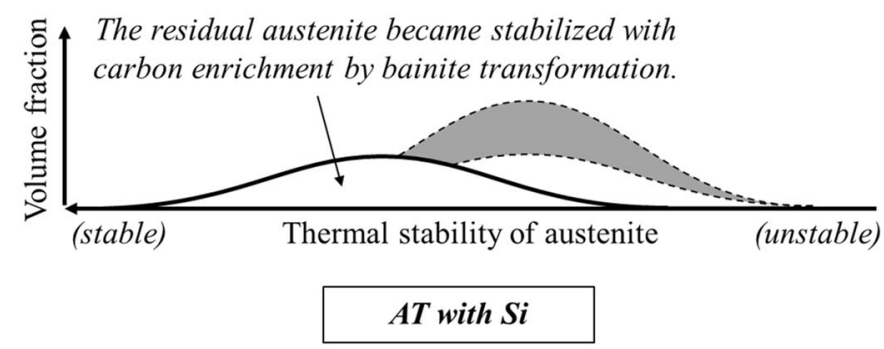

(6)

Fig. 13 - Schematics for the explanation of the $M_{\mathrm{s}}$ behavior. NQ and AT are the normal quench and austempering, respectively. (1), (3), and (5) show the transformation behavior after austenitization. (2), (4), and (6) correspond to the thermal stability distribution of untransformed austenite to martensite transformation at $M_{\mathrm{s}}$ in (1), (3), and (5), respectively.

content (Figure 13(6)). Therefore, $M_{\mathrm{s}}$ after austempering decreases from that in NQ (Figure 13(5)).

Figure 14 shows similar schematics to explain the $M_{\mathrm{r}}$ behaviors during the TSQ and RAT treatments in this study. The role of the first quench, which produces pre-existing martensite, is exceedingly important. Figures 14(1) and (2) show the case of the TSQ specimen, in which $V_{\mathrm{M}}=0.50$. During the first quench to $T_{\mathrm{Q}}$, the martensite transformation proceeds and expends the unstable half of prior austenite. After a short break with reheating, the martensite transformation during the final quench to room temperature is determined by the most unstable region in the stability distribution, Figure 14(2); therefore, it restarts just below $T_{\mathrm{Q}}$, which is equal to the measured $M_{\mathrm{r}}$.

Figure 14(3) describes the transformation behavior in the RAT sample without silicon. After the partial martensite transformation during the first quench to $T_{\mathrm{Q}}$, the bainite transformation proceeds above $M_{\mathrm{s}}$, and the martensite transformation restarts at $T_{\mathrm{Q}}$ during the final quench to room temperature. This result suggests 


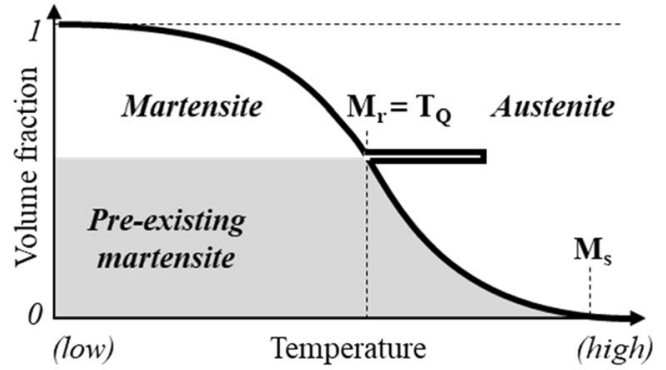

(1)

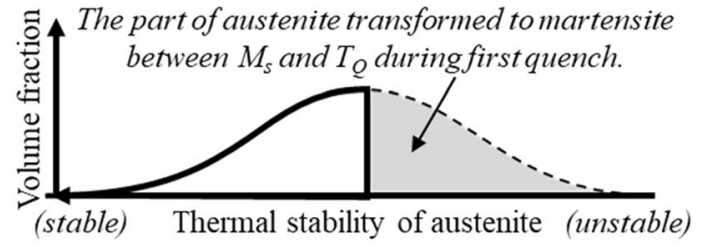

(2)

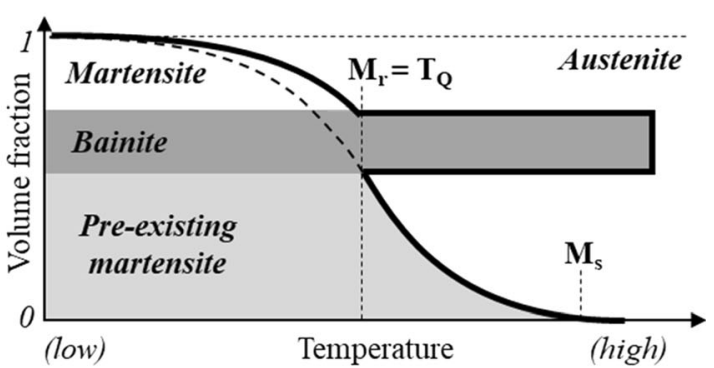

(3)

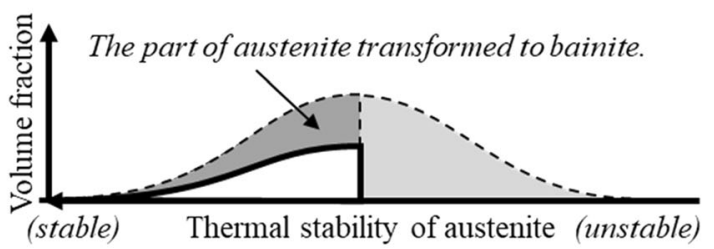

(4)

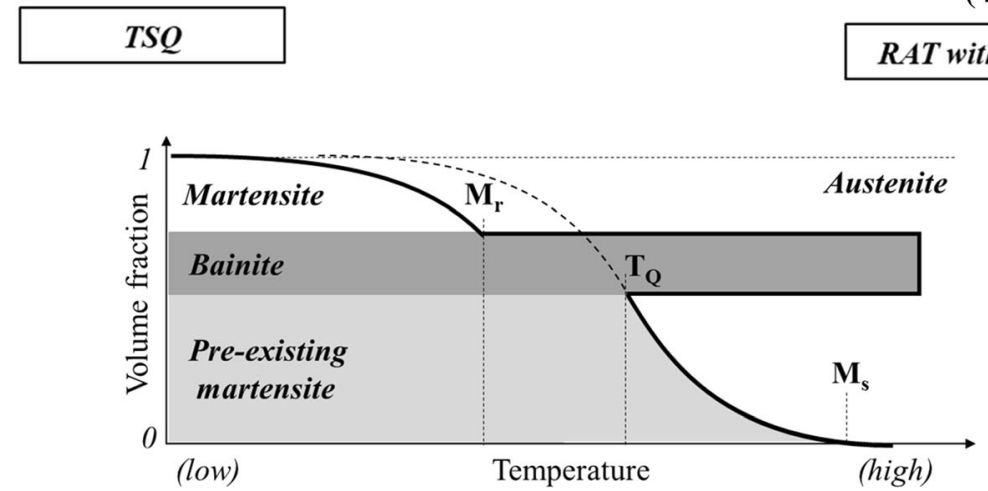

(5)

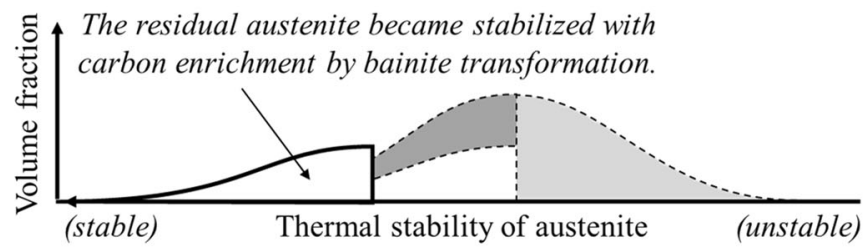

(6)

\section{RAT with $\mathrm{Si}$}

Fig. 14-Schematics for the explanation of the $M_{\mathrm{r}}$ behavior. TSQ and RAT are the two-step quench and reheat austempering, respectively. (1), (3), and (5) show the transformation behavior after austenitization. (2), (4), and (6) correspond to the thermal stability distribution of untransformed austenite to martensite transformation at $M_{\mathrm{r}}$ in (1), (3), and (5), respectively.

that the stability distribution of austenite is not affected substantially by the bainite transformation during austempering, as in the AT sample shown in Figure 13(4). The stability distribution of the residual austenite after the first quench reduces its height without changing its shape through the bainite transformation (Figure 14(4)). The most unstable region in this distribution is as stable as that in the TSQ sample, Figure 14(2), and is more stable than that in the AT sample, Figure 13(4), by the supercooling during the first quench from $M_{\mathrm{S}}$ in the NQ sample to $T_{\mathrm{Q}}$. The untransformed austenite after the first quench memorizes the supercooling, regardless of the bainite transformation.

The results of this study suggest that this supercooling memory is expressed by the carbon concentration in untransformed austenite. Figure 14(5) shows the transformation behavior in the RAT sample with silicon. The carbon content in untransformed austenite increases through the carbon distribution from bainite to austenite; therefore, the stability distribution after austempering shown in Figure 14(6) shifts to the stable side from 
that of the 0Si sample in Figure 14(4). If the carbon partitioning from pre-existing martensite to untransformed austenite is negligible, the carbon content in austenite depends on $f_{\mathrm{B}}$. When $f_{\mathrm{B}}$ in Figure $14(5)$ is as much as that in Figure 13(5), their untransformed austenite stabilizations, $T_{\mathrm{Q}}-M_{\mathrm{r}}$ and $M_{\mathrm{s}}(\mathrm{NQ})-M_{\mathrm{s}}(\mathrm{AT})$, are similar. However, the untransformed austenite after austempering in the RAT sample with $\mathrm{Si}$ is more stable than that in the AT sample by the supercooling in the first quench, $M_{\mathrm{s}}-T_{\mathrm{Q}}$.

\section{Mechanism of Supercooling Memory in RAT Treatment}

Some determining factors of martensite transformation behavior in steel are well known - chemical compositions, ${ }^{[31,38]}$ strain, ${ }^{[39,40]}$ stress, ${ }^{[41-43]}$ and nucleation site, ${ }^{[4]}$ especially prior austenite grain size, ${ }^{[4-46]}$ etc. Although we guess that the effect of carbon partitioning is as great as in the normal bainite transformation in Figure 11, the mechanism of this supercooling memory effect is not clear in this study. However, we are able to present some ideas.

In this study, the pre-existing martensite in the $0 \mathrm{Si}$ alloy was surrounded by the bainite (Figure 3). However, the untransformed austenite certainly remembered the supercooling, despite $V_{\mathrm{M}}$ and $V_{\mathrm{B}}$ (Figures 4(3) and $6)$. This result suggests that the strain induced into the untransformed austenite by the martensite transformation was not the main driver of this phenomenon, because it changes according to distance from martensite. ${ }^{[47]}$

The untransformed austenite grain size and shape depends, not only on $V_{\mathrm{M}}$ and $V_{\mathrm{B}}$, but also on silicon content, as the morphology of bainite changes with silicon $^{[22]}$ (Figures 3 and 7). This suggests that the austenite grain character is not dominant in this study.

There are no results regarding the effect of other nucleation sites (e.g., defects in austenite grain ${ }^{[44]}$ ), local distribution of chemical compositions, ${ }^{[48]}$ and macroscopic segregation. ${ }^{[49]}$ Some of these factors controlling the martensite transformation behavior may be the dominant factor of this result. It is necessary to clarify this phenomenon to explain not only the effect of martensite but also that of unrelated bainite.

\section{Effect of Supercooling Memory in RAT Treatment}

The untransformed austenite remembers the supercooling of the first quench at the martensite transformation restart. Figures 5 and 10 indicate that $M_{\mathrm{r}}$ decreases according to the supercooling in the untransformed austenite with the same carbon content. If the carbon concentration in austenite from bainite and/or pre-existing martensite is sufficient, $M_{\mathrm{r}}$ is approximately room temperature; thus, the part of the untransformed austenite transforms to fresh martensite, whereas the other part stays as austenite ${ }^{[5,7,17]}$ at room temperature. The fraction of retained austenite is expected to be larger as $M_{\mathrm{r}}$ decreases. Therefore, it becomes larger with the increase in supercooling in the untransformed austenite with same carbon content.
Santofimia et al. ${ }^{[12]}$ showed that the volume fraction of retained austenite containing the same carbon content in QP steel depends on $T_{\mathrm{Q}}$ and has a peak at $503 \mathrm{~K}$ (230 ${ }^{\circ} \mathrm{C}$ ), which is $108 \mathrm{~K}$ lower than $M_{\mathrm{s}}$ during NQ. They explain this result as the competition between the increase in the volume fraction of pre-existing martensite, which is the source of the carbon concentration, and the decrease in the volume fraction of untransformed austenite after austempering, which is the denominator of retained austenite. However, the increase in the retained austenite with $T_{\mathrm{Q}}$ from $M_{\mathrm{s}}$ to $503 \mathrm{~K}\left(230{ }^{\circ} \mathrm{C}\right)$ is explainable through the supercooling memory effect. The supercooling at the peak, $108 \mathrm{~K}$, corresponds to a carbon concentration of 0.7 mass $\mathrm{pct}^{[30]}$ for 0.9 mass pet solute carbon in retained austenite in their paper. The effect of carbon concentration into austenite would overlap that of supercooling; however, the detail was not clear. Allain et al. ${ }^{[10,50]}$ measured phase fractions with austenite lattice parameter during RAT pattern by in-situ high-energy X-ray diffraction experiment. Using synchrotron X-ray diffraction $^{[10,50-52]}$ would be useful to clarify the stabilization behavior of austenite.

The retained austenite is a very good constituent to increase the strength of steel with good formability via the transformation induced plasticity effect. ${ }^{[53]}$ Low-alloyed TRIP steels, ${ }^{[17,32,54]}$ QP steels, ${ }^{[5,7,25]}$ and other advanced steels ${ }^{[55-58]}$ contain retained austenite. The strain induced transformation behavior from retained austenite to martensite is described with $M_{\mathrm{s}}^{[32,59-61]}$; thus, the retained austenite whose $M_{\mathrm{s}}$ decreases by the supercooling memory effect would be more stable for plastic deformation than that without the supercooling memory effect. In multi-structural steel, the strengthening of steel consistently increases the stress, ${ }^{[62,63]}$ whereas the strain induced transformation is accelerated. ${ }^{60,61,64]}$ Therefore, the stable austenite (Figure 14(6)) would be suitable for ultra-high-strength steel.

\section{SUMMARY}

The aim of this study involved clarifying the martensite transformation behavior during the quench and austempering pattern, the so-called QP process. We evaluated $M_{\mathrm{s}}$ and $M_{\mathrm{r}}$ during several heat treatments, namely NQ, TSQ, AT, and RAT, in Fe-8Ni-0.2C alloys with and without Si.

1. In the 0Si alloy, $M_{\mathrm{r}}$ in the RAT sample containing pre-existing martensite, upper bainite, and fresh martensite was equal to $T_{\mathrm{Q}}$, as in the TSQ sample. The progress of the bainite transformation did not affect the martensite transformation start and restart.

2. In the $1 \mathrm{Si}$ alloy, the upper bainite, which is generated at $673 \mathrm{~K}\left(400{ }^{\circ} \mathrm{C}\right)$, contained fewer carbide particles than contained in the 0Si alloy, and $M_{\mathrm{s}}$ in the AT sample decreased parabolically with the progress of bainite transformation. $M_{\mathrm{r}}$ in the TSQ samples and RAT samples containing a small amount of bainite reached as high as $T_{\mathrm{Q}}$. 
However, $M_{\mathrm{r}}$ in all the RAT samples decreased parabolically from $T_{\mathrm{Q}}$ with the progress of bainite transformation.

3. The stabilization behavior with the bainite transformation progress parameter $f_{\mathrm{B}}$ in the 1Si RAT samples, $T_{\mathrm{Q}}-M_{\mathrm{r}}$, was similar to that in the AT samples, the difference from $M_{\mathrm{s}}$ in the NQ sample and that in the AT sample. This suggests that the stabilization of untransformed austenite during the RAT pattern in this study depends on the supercooling during the first quench, $M_{\mathrm{s}}(\mathrm{NQ})-T_{\mathrm{Q}}$, and the carbon distribution from bainite to untransformed austenite.

4. These results indicate that the entire untransformed austenite memorized the self-stabilization during the first quench, and this memory was not fundamentally affected by the bainite transformation at $673 \mathrm{~K}\left(400{ }^{\circ} \mathrm{C}\right)$. Moreover, the stabilization by the carbon concentration in untransformed austenite was added to this memory. This phenomenon would affect the microstructure development and mechanical properties during the RAT heat treatment.

\section{ACKNOWLEDGMENTS}

The authors would like to express their sincere thanks to Dr. Tadashi Maki (Honorary professor of Kyoto University, Japan) for the stimulating discussions and his valuable comments.

\section{REFERENCES}

1. K. Zhu, H. Chen, J.-P. Masse, O. Bouaziz, and G. Gachet: Acta Mater., 2013, vol. 61, pp. 6025-36.

2. M. Takahashi: ISIJ Int., 2015, vol. 55, pp. 79-88.

3. O. Bouaziz, H. Zurob, and M.X. Huang: Steel Res. Int., 2013, vol. 84, pp. 937-47.

4. J.N. Hall and J.R. Fekete: Automotive Steels: Design, Metallurgy, Processing and Applications, 1st Ed., edited by R. Rana and S.B. Singh, Elsevier, 2017, pp. 19-45.

5. J. Speer, D.K. Matlock, B.C. De Cooman, and J.G. Schroth: Acta Mater., 2003, vol. 51, pp. 2611-22.

6. D.K. Matlock and J.G. Speer: Design Consideration for the next Generation of Advanced High Strength Sheet Steels, Proc. 3rd Int. Conf. on Structural Steels, ed. by H. C. Lee, Korean Institute of Metals and Materials, Seoul, 2006, p. 774.

7. D.V. Edmonds, K. He, F.C. Rizzo, B.C. De Cooman, D.K. Matlock, and J.G. Speer: Mater. Sci. Eng. A, 2006, vols. 438-440, pp. 25-34.

8. C.Y. Wang, J. Shi, W.Q. Cao, and H. Dong: Mater. Sci. Eng. A, 2010, vol. 527, pp. 3442-49.

9. M.J. Santfimia, L. Zhao, and J. Sietsma: Metal. Mater. Trans. A, 2011, vol. 42A, pp. 3620-26.

10. S.Y.P. Allain, G. Geandier, J.-C. Hell, M. Soler, F. Danoix, and M. Gouné: Metals, 2017, vol. 7, p. 232.

11. A.J. Clarke, J.G. Speer, D.K. Matlock, F.C. Rizzo, D.V. Edmonds, and M.J. Santofimia: Scripta Mater., 2009, vol. 61, pp. 149-52.

12. M.J. Santfimia, L. Zhao, R. Petrov, C. Kwakernaak, W.G. Sloof, and J. Sietsma: Acta Mater., 2011, vol. 59, pp. 6059-68.

13. D. De Knijf, E.P. Da Silva, C. Föjer, and R. Petrov: Mater. Sci. Technol., 2015, vol. 31, pp. 817-28.
14. E. De Moor, S. Lacroix, A.J. Clarke, J. Penning, and J.G. Speer: Metall. Mater. Trans. A, 2008, vol. 39A, pp. 2586-95.

15. E. De Moor, J.G. Speer, D.K. Matlock, J.-H. Kwak, and S.-B. Lee: ISIJ Int., 2011, vol. 51, pp. 137-44.

16. D.T. Pierce, D.R. Coughlin, D.L. Williamson, K.D. Clarke, A.J. Clarke, J.G. Speer, and E. De Moor: Acta Mater., 2015, vol. 90 , pp. $417-30$.

17. Y. Sakuma, O. Matsumura, and H. Takechi: Metall. Trans. A, 1991, vol. 22A, pp. 489-98.

18. D. Quidort and Y.J.M. Brechet: Acta Mater., 2001, vol. 49, pp. $4161-70$.

19. S.A. Kahn and H.K.D.H. Bhadeshia: Mater. Sci. Engng., 1990, vol. A129, pp. 257-72.

20. S.M.C. van Bohemen and D.N. Hanlon: Int. J. Mater. Res., 2012, vol. 103, pp. 987-91.

21. H. Kawata, K. Hayashi, N. Sugiura, N. Yoshinaga, and M. Takahashi: Mater. Sci. Forum, 2009, vols. 638-642, pp. 3307-12.

22. Y. Toji, H. Matsuda, and D. Raabe: Acta Mater., 2016, vol. 116, pp. $250-62$.

23. J. Sun and H. Yu: Mater. Sci. Eng. A, 2013, vol. 586, pp. 100-07.

24. X.C. Xiong, B. Chen, M.X. Huang, J.F. Wang, and L. Wang: Scripta Mater., 2013, vol. 68, pp. 321-24.

25. D. De Knijf, C. Föjer, L.A.I. Kestens, and R. Petrov: Mater. Sci. Eng. A, 2015, vol. 638, pp. 219-27.

26. H. Kawata, K. Hayashi, N. Yoshinaga, and M. Takahashi: Proceedings of the 1st International Conference on Automobile Steel (ICAS2016) \& the 3rd International Conference on High Manganese Steels (HMnS2016), Chengdu, China, 2016, pp. 402-45.

27. M. Cohen: Met. Prog., 1948, vol. 56, pp. 823-26.

28. Q. Huang, B.C. De Cooman, H. Biermann, and J. Mola: Metall. Mater. Trans. A, 2016, vol. 47A, pp. 1947-59.

29. N. NakadaNakada, Y. Ishibashim, T. Tsuchiyama, and S. Takaki: Acta Mater., 2016, vol. 110, pp. 95-102.

30. J. Wang and S. van der Zwaag: Metall. Mater. Trans. A, 2001, vol. $32 \mathrm{~A}$, pp. $1527-39$.

31. J. Zhao: Mater. Sci. Technol., 1992, vol. 8, pp. 997-1003.

32. A. Perlade, O. Bouaziz, and Q. Furnémont: Mater. Sci. Eng. A, 2003, vol. 156, pp. 145-52.

33. D.P. Koistinen and R.E. Marburger: Acta Metall., 1959, vol. 7, pp. 59-60.

34. S.M.C. Boheman and J. Sietsma: Metall. Mater. Trans. A, 2009, vol. 40 A, pp. $1059-68$.

35. A.R. Entwisel: Metall. Trans., 1971, vol. 2, pp. 2395-2407.

36. Y. Imai and M. Izumiyama: Sci. Rep. Res. Inst. Tohoku Univ. Ser. Phys. Chem. Metall., 1959, vol. 11, pp. 393-400.

37. M.E. Blanter and B.G. Serebrennikova: Met. Sci. Heat Treat., 1972, vol. 14, pp. 567-70.

38. A. Borgenstam and M. Hillert: Acta Mater., 1997, vol. 45, pp. 2079-91.

39. R.H. Richman and G.F. Bolling: Metall. Trans., 1971, vol. 2, pp. 2451-62.

40. M. Zhang, Y.H. Wang, C.L. Zheng, F.C. Zhang, and T.S. Wang: Mater. Sci. Eng. A, 2014, vol. 596, pp. 9-14.

41. S.V. Radcliffe and M. Schatz: Acta Metall., 1962, vol. 10, pp. 201-07.

42. G.F. Bolling and R.H. Richman: Scripta Metall., 1970, vol. 4, pp. 539-44.

43. V.D. Blank and E.I. Estrin: Phase Transitions in Solids Under High Pressure, CRC Press, Boca Raton, 2013.

44. A.S. Sastri and D.R.F. West: J. Iron Steel Inst., 1965, vol. 203, pp. $138-45$.

45. S. Takaki, K. Fukunaga, J. Syarif, and T. Tsuchiyama: Mater. Trans., 2004, vol. 45, pp. 2245-51.

46. H.S. Yang and H.K.D.H. Bhadeshia: Scripta Mater., 2009, vol. 60 , pp. 493-95

47. G. Miyamoto, A. Shibata, T. Maki, and T. Furuhara: Acta Mater., 2009, vol. 57, pp. 1120-31.

48. M. Gouné, F. Danoix, S. Allain, and O. Bouaziz: Scripta Mater., 2013, vol. 68, pp. 1004-07.

49. H. Kawata, K. Fujiwaram, and M. Takahashi: ISIJ Int., 2017, vol. 57, pp. 1866-73.

50. S.Y.P. Allain, G. Geandier, J.C. Hell, M. Soler, F. Danoix, and M. Gouné: Scripta Mater., 2017, vol. 131, pp. 15-18.

51. W. Wu, Y.-W. Wang, P. Makrygiannis, F. Zhu, G.A. Thomas, L.G. Hector, Jr, X. Hu, X. Sun, and Y. Ren: Mater. Sci. Eng. A, 2018, vol. 711, pp. 611-23. 
52. F. Abu-Farha, X. Hu, X. Sun, Y. Ren, L.G. Hector, Jr, G. Thomas, and T.W. Brown: Metall. Mater. Trans. A, 2018, vol. 49A, pp. 2583-96.

53. V.F. Zackay, E.R. Parker, D. Fahr, and R. Bush: Trans. ASM, 1967, vol. 60, pp. 252-59.

54. B.C. De Cooman: Curr. Opin. Solid State Mater. Sci., 2004, vol. 8, pp. 285-303.

55. T. Furukawa: Mater. Sci. Technol., 1989, vol. 5, pp. 465-70.

56. C. Garcia-Mateo, F.G. Caballero, and H.K.D.H. Bhadeshia: ISIJ Int., 2003, vol. 43, pp. 1238-43.

57. K. Sugimoto, A. Kanda, R. Kikuchi, S. Hashimoto, T. Kashima, and S. Ikeda: ISIJ Int., 2002, vol. 42, pp. 910-15.

58. L. Liu, B. He, and M. Huang: Adv. Eng. Mater., 2018, vol. 20, p. 1701083 .
59. R.G. Stringfellow, D.M. Parks, and G.B. Olson: Acta Metall. Mater., 1992, vol. 40, pp. 1703-16.

60. H. Onodera, H. Oka, and I. Tamura: J. Jpn. Inst. Met. Mater., 1978, vol. 42, pp. 898-905 (in Japanese).

61. I. Tamura: Met. Sci., 1982, vol. 16, pp. 245-53.

62. S. Allain and O. Bouaziz: Mater. Sci. Eng. A, 2008, vol. 496, pp. 329-36.

63. S. Harjo, N. Tsuchida, T. Shinohara, and W. Gong: Sci. Rep., 2017, vol. 7, p. 15149

64. H. Kawata, T. Yasutomi, S. Shirakami, K. Nakamura, and E. Sakurada: ISIJ Int., 2021, vol. 61.

Publisher's Note Springer Nature remains neutral with regard to jurisdictional claims in published maps and institutional affiliations. 